\title{
Reintroducing Sborgite: Crystallization through Exposure of Sodium Borosilicate Glasses to Moisture
}

\author{
Yuxuan Gong ${ }^{1}$, Chokchai Yatongchai ${ }^{1}$, Anthony W. Wren ${ }^{1}$, Nathan P. Mellott ${ }^{1}$
}

\section{$\underline{\text { Abstract }}$}

Sborgite $\left(\mathrm{Na}\left[\mathrm{B}_{5} \mathrm{O}_{6}(\mathrm{OH})_{4}\right] \cdot 3 \mathrm{H}_{2} \mathrm{O}\right)$ is a rare mineral, naturally occurring in only 2 known locations worldwide: California, USA and Larderello, Italy. Little is known of this mineral given its' rarity in the natural world as well the inability, until now, to be produced in a single crystalline product. For the first time, we reported a single crystalline sborgite crystallization phenomenon caused by exposure of two different sodium borosilicate glasses to moisture. In this study, two homogeneous and two phase separated borosilicate glasses were prepared and exposed to moisture at room temperature $\left(\sim 25^{\circ} \mathrm{C}\right)$ for up to 1 month. The powders were characterized by X-ray diffraction (XRD) and environmental scanning electron microscopy (ESEM). The results showed that exposure of all sodium borosilicate glasses to moisture can lead to crystallization of sborgite micro-crystals with a column-like morphology. In addition, it is shown that exposure of homogeneous glasses to humidity results in the formation of more highly crystalline sborgite than phase separated glasses of equal composition.

Keywords: sborgite; single crystalline product; crystallization in moisture; SEM 


\section{Introduction}

Sborgite was first discovered by Curzio Cipriani ${ }^{1}$, who found the mineral associated with borax and thenardite near volcanic vents ("soffioni" in Italian) in boriferous areas of Larderello, Italy. Sborgi first synthesized the mineral in his research of the ternary $\mathrm{Na}_{2} \mathrm{O}-\mathrm{B}_{2} \mathrm{O}_{3}-\mathrm{H}_{2} \mathrm{O}$ system, and hence the mineral was named after him. Due to the limited localities of naturally occurring sborgite ${ }^{1,2}$, no extensive crystallographic study was performed prior to Stephano Merlino ${ }^{3}$. Stephano constructed the crystal structure of sborgite by X-ray diffraction. Sborgite, as reported by Stephano, has a structure with low packing density; and hence shows potential for applications such as drug delivery, energy harvesting, and advanced materials tailoring ${ }^{4,5}$.

Sborgite can be synthesized by precipitation from an aqueous boric acid-sodium hydroxide solution as reported by Takao $\mathrm{Oi}^{6}$. However, to the best of the authors' knowledge, the crystallization of sborgite has always been associated with simultaneous crystallization of borax, santite and sassolite $^{7}$; synthesis of single crystalline product form sborgite has yet to be reported. It has been shown by previous authors that hydrous borates, in particular sassolite can be synthesized through exposure of phase separated borosilicate glasses to humidity ${ }^{8}$. Therefore, it is of interest whether sborgite could be prepared through exposure of homogeneous or phase separated sodium-rich borosilicate glasses.

In this study, we successfully synthesized single crystalline form sborgite through exposure of homogeneous and phase separated glasses to humidity, using a novel moisture chamber. Four distinct glasses; two homogeneous and two phase separated glasses were prepared, powdered, and exposed to moisture for up to 1 month. Exposed powders were characterized by X-ray diffraction and scanning electron microscopy. For the very first time, we report a single crystalline phase sborgite formation. 


\section{$\underline{2 \text { Materials and Methods }}$}

\subsection{Materials and Formulation}

Two homogenous glasses (1) $9.4 \mathrm{Na}_{2} \mathrm{O}-25.4 \mathrm{~B}_{2} \mathrm{O}_{3}-65.2 \mathrm{SiO}_{2}$ and (2) $13.9 \mathrm{Na}_{2} \mathrm{O}-36.0 \mathrm{~B}_{2} \mathrm{O} 3-50.1 \mathrm{SiO}_{2}$ (referred to as pre-droplet and pre-spinodal from this point forward, eg. Table1) were melted in platinum crucible with reagent level $\mathrm{Na}_{2} \mathrm{CO}_{3}, \mathrm{~B}_{2} \mathrm{O}_{3}$ and $\mathrm{SiO}_{2}$ (Fisher Scientific, USA) following the processing parameters listed in Table 1 . The glass melts were air quenched on a stainless steel plate pre-heated at $500{ }^{\circ} \mathrm{C}, \quad$ Phase separation of both glass were achieved by heat treatment using previously reported methods $s^{9,10}$. Heat treatment of glass (1) at $610{ }^{\circ} \mathrm{C}$ for 10 hours resulted in a phase seperated glass with a droplet in matrix microstructure ${ }^{9}$ and heat treatment of glass (2) at $600{ }^{\circ} \mathrm{C}$ for 24 hours resulted in a phase separated glass with a spinodal microstructure ${ }^{10}$.

Table 1 Nomenclature, Batch Composition and Processing Parameters of Glasses

\begin{tabular}{|c|c|c|c|c|c|c|}
\hline Nomenclature & $\begin{array}{c}\text { Batch } \\
\text { Composition } \\
(\mathrm{mol} \%)\end{array}$ & $\begin{array}{c}\text { Melting } \\
\text { Temperature } \\
\left({ }^{\circ} \mathrm{C}\right)\end{array}$ & $\begin{array}{l}\text { Melting } \\
\text { Duration } \\
\text { (hour) }\end{array}$ & $\begin{array}{c}\text { Heat } \\
\text { Treatment } \\
\text { Temperature } \\
\left({ }^{\circ} \mathrm{C}\right)\end{array}$ & $\begin{array}{c}\text { Heat } \\
\text { Treatment } \\
\text { Duration } \\
\text { (hour) }\end{array}$ & $\begin{array}{c}\text { Physical } \\
\text { Appearance }\end{array}$ \\
\hline Pre-droplet & $\begin{array}{c}13.9 \mathrm{Na}_{2} \mathrm{O}- \\
36.0 \mathrm{~B}_{2} \mathrm{O}_{3^{-}} \\
50.1 \mathrm{SiO}_{2}\end{array}$ & 1250 & 1 & N/A & N/A & Clear \\
\hline Pre-spinodal & $\begin{array}{c}\text { 9.4 } \mathrm{Na}_{2} \mathrm{O}- \\
25.4 \mathrm{~B}_{2} \mathrm{O}_{3^{-}} \\
65.2 \mathrm{SiO}_{2}\end{array}$ & 1400 & 1 & N/A & N/A & Clear \\
\hline Droplet & $\begin{array}{c}13.9 \mathrm{Na}_{2} \mathrm{O}_{-}^{-} \\
36.0 \mathrm{~B}_{2} \mathrm{O}_{3^{-}} \\
50.1 \mathrm{SiO}_{2}\end{array}$ & 1250 & 1 & 610 & 10 & $\begin{array}{l}\text { White \& } \\
\text { Cloudy }\end{array}$ \\
\hline Spinodal & $\begin{array}{c}9.4 \mathrm{Na}_{2} \mathrm{O}_{-}^{-} \\
25.4 \mathrm{~B}_{2} \mathrm{O}_{3}- \\
65.2 \mathrm{SiO}_{2}\end{array}$ & 1400 & 1 & 600 & 24 & $\begin{array}{l}\text { Bluish \& } \\
\text { Clear }\end{array}$ \\
\hline
\end{tabular}

\subsection{Moisture Chamber Setup}

The glasses were pulverized into fine particles with a Gyro Mill (Glen-Creston Ltd., UK). Pulverized glass powders were ultrasonically cleaned in acetone for 10 minutes, and then dried in vacuum at $90{ }^{\circ} \mathrm{C}$. The prepared, cleaned glass powders were placed into an in-float petri dish setup 
as shown in Fig.1e; later, the petri dishes were placed into a vacuum desiccator half-filled with DIwater and sealed with Parafilm as shown in Fig.1f. All components of the moisture chamber were rinsed with DI-water and dried in nitrogen gas flow before usage. The glass powders were exposed in this setup from 1 week to 1 month at room temperature $\left(\sim 25^{\circ} \mathrm{C}\right)$. After exposure and prior to any analyses the powders were vacuum dried at $90{ }^{\circ} \mathrm{C}$ for $3 \mathrm{hrs}$.

\subsection{Phase Identification}

Powder diffraction was performed on all as-prepared and post-exposure glass powders (pre-spinodal, pre-droplet, spinodal and droplet) with an X-ray diffractometer (D2 Phaser, Bruker Inc., USA). Powder diffractions performed on the fresh post-exposure glass powders show no observable difference before/after drying. The emission current was set to $10 \mathrm{~mA}$ with a Cuk $\alpha$ source. A scanning range from $10^{\circ}$ to $70^{\circ}$ and a voltage of $30 \mathrm{kV}$ were used in all measurements. MDI Jade 8.0 software with the ICDD (International Center of Diffraction Data) PDF4+ database was used for the phase identification. Crystallographic construction was performed on CrystalMaker software (version 2.2.4, CrystalMaker Ltd., USA) using previously reported crystallographic data ${ }^{3}$.

\subsection{Micro-structural Characterization}

Glass powders exposed to moisture for 1 month were treated with $25 \% \mathrm{HF}$ for 10 seconds and imaged using an Environmental Scanning Electron Microscope (ESEM, Quanta 200, Philips-FEI corp., Netherlands). The ESEM was operated at low vacuum $\left(6 \mathrm{e}^{-1}\right.$ torr, emission current $\left.=272 \mu \mathrm{A}\right)$ with an acceleration voltage of $20 \mathrm{kV}$. 


\section{$\underline{3 \text { Results and Discussion }}$}

\subsection{As-prepared glasses}
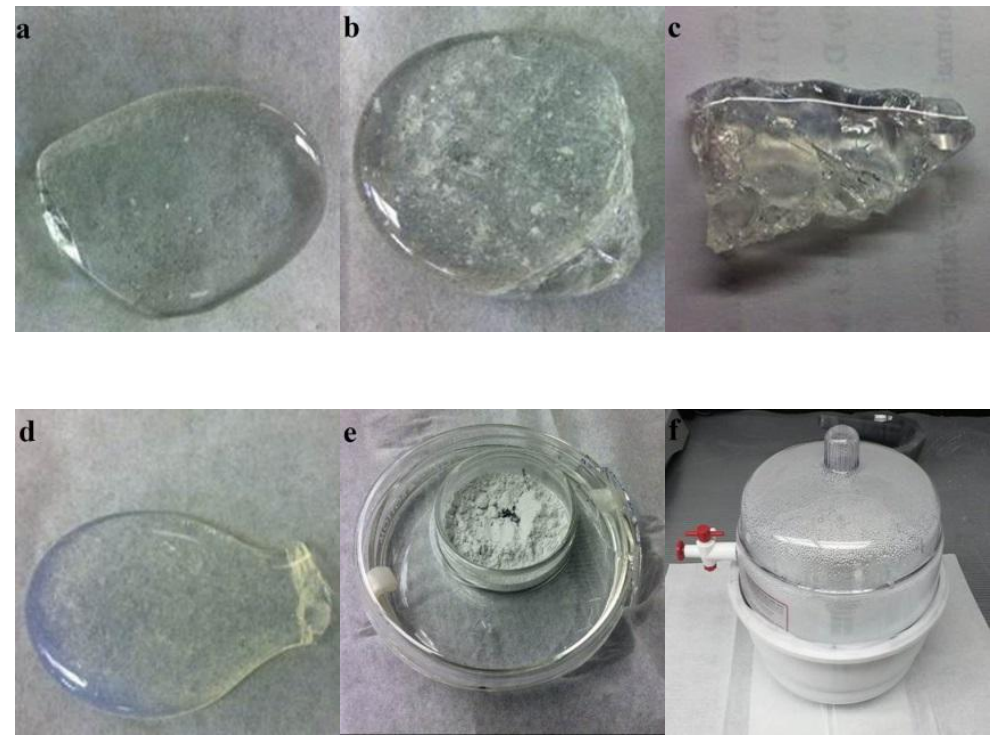

Figure 1 Photos of a) pre-droplet glass, b) pre-spinodal glass, c) droplet glass, d) spinodal glass, e) in-float petri dish setup and f) moisturizing vacuum desiccator.

Fig.1a to Fig.1d show freshly prepared homogeneous pre-droplet, homogeneous pre-spinodal, phase separated droplet, and phase separated spinodal glass respectively. Pre-droplet and pre-spinodal glass shown in Fig.1a and Fig.1b exhibit an optically clear appearance after quenching in air. The phase separated droplet glass appears cloudy white as shown in Fig.1c while the phase separated spinodal glass shows a bluish clear appearance (Fig. 1d). The optical effects observed in phase separated glassed are likely due to the density/refractive index contrast of modifier rich region and network-former rich region as reported by McGahay and Tomozawa ${ }^{11}$. Liquid phase separation of glass is often due to competition of oxygen coordination between network-modifiers and networkformers, resulting in immiscible modifier-rich and network former-rich regions within the glass ${ }^{11}$. Given the compositions used here, two distinct regions are expected; (1) a silica rich region and (2) 
a sodium and boron rich region ${ }^{9,10}$. Thus, the density contrast of these two distinct regions formed after heat treatment of homogeneous glasses results in the physical appearance observed in this study.

\section{$3.2 X$-ray diffraction of moisturized glasses}

Powder X-ray diffraction was performed on all four glass powders prior to exposure to moisture (Fig.2a). A broad, featureless hump is observed for all glasses, indicating all four as-prepared glasses to be X-ray amorphous.
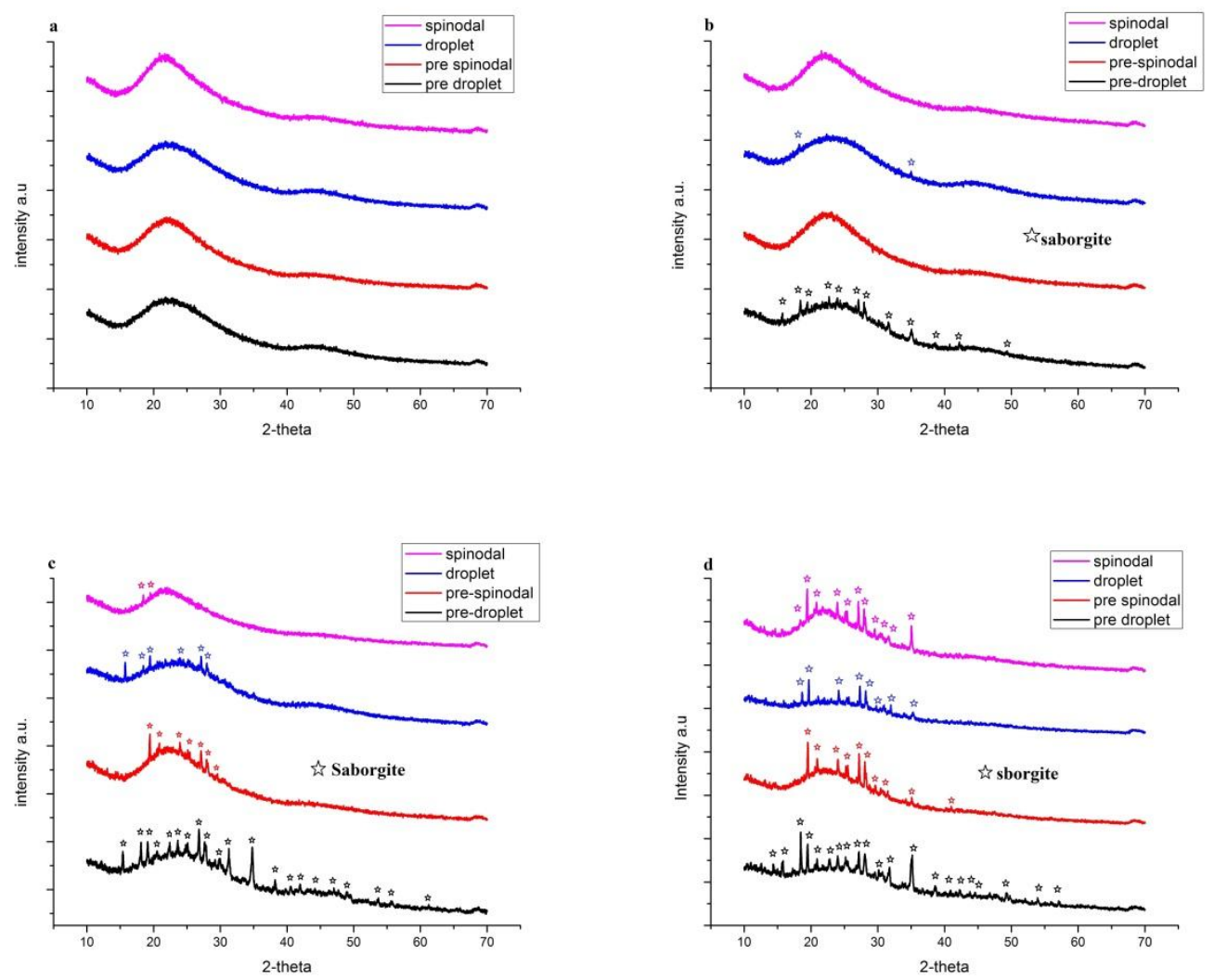

Figure 2 XRD patterns of all four glasses as a) un-moisturized, b) moisturized for 1 week, c) moisturized for 2 weeks and d) moisturized for 1 month. 
Fig.2b shows XRD patterns of pre-droplet, pre-spinodal, droplet and spinodal glasses after exposure to moisture for 1 week. Crystalline diffraction peaks were identified for the pre-droplet glass and droplet glass while both the pre-spinodal and spinodal glass show no evidence of crystallinity. The XRD pattern of pre-droplet and droplet exposed to moisture for 1 week matches the diffraction pattern of sborgite (PDF\#24-1056) with no identifiable peak shift or resolved peaks. The pre-droplet glass appears to have developed a more highly crystalline material than the droplet glass, as evidenced by a greater number and intensity of diffraction peaks. In particular, the diffraction peaks at $\sim 18.34^{\circ}$ and $34.85^{\circ}$ corresponds to the $(-1,3,1)$ and $(-4,4,2)$ planes of sborgite.

After humidity exposure for 2 weeks, the pre-spinodal and spinodal glasses also started to develop crystalline phase as shown in Fig.2c. The crystalline diffraction peaks observed in pre-spinodal and spinodal glasses were identified also sborgite (PDF\#24-1056). The pre-spinodal glass shows a more developed crystalline structure comparing to spinodal glass, with seven diffraction planes observed. In Fig.2c, the XRD pattern of pre-droplet glasses after exposure to moisture for 2 weeks shows a fully developed crystalline phase while the diffraction pattern of droplet glasses is less developed. Fig. $2 d$ shows the XRD pattern of all glasses after exposure for 1 month, and diffraction peaks in each diffraction pattern tend to more developed comparing to Fig.2b and Fig.2c.

Fig.2b through Fig.2d exhibited the trend of continuing crystal growth with increasing exposure time for all interested glasses, as indicated by the development of diffraction planes; also, the XRD patterns of each moisturizing time span show that the sborgite crystalline phase of homogenous glasses (pre-droplet, pre-spinodal) is more developed compared to the corresponding phase separated glasses (droplet, spinodal). Among all the diffraction peaks identified from Fig.2b to Fig.2d, the $(-1,3,1)$ plane is most prominent and tends to appear in diffraction patterns preferentially. No other crystalline phase was identified among all the XRD patterns. 


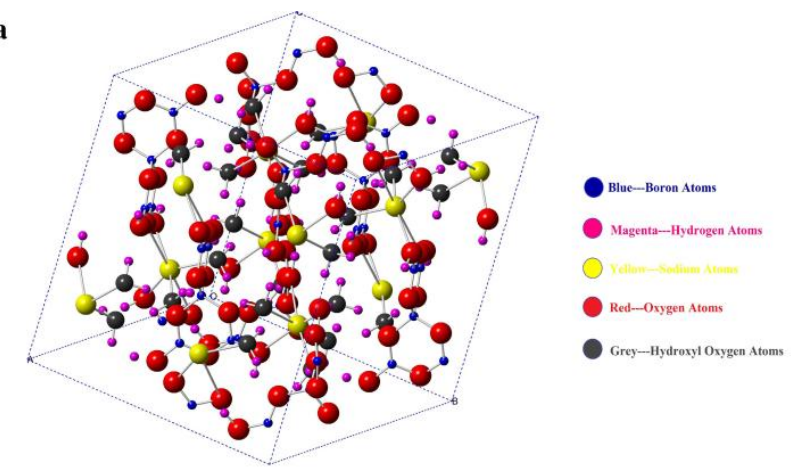

b

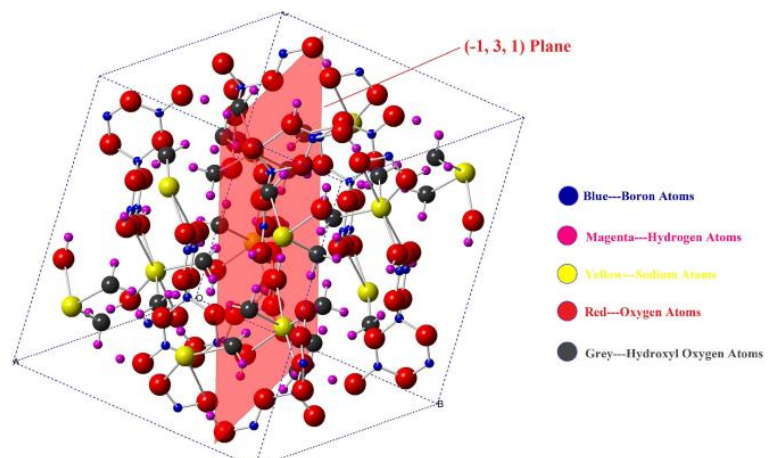

Figure 3 a) unit cell crystallographic presentation of sborgite, b) unit cell crystallographic presentation of sborgite with $(-1,3,1)$ plane as red-shaded plane.

In order to conceptualize and visualize the crystallographic structure of sborgite as observed here, CrystalMaker was used to construct the unit cell as shown in Fig.3a. In Fig.3a, the coordination of sborgite crystal consists of $\left[\mathrm{NaOH}_{4} \cdot 2 \mathrm{H}_{2} \mathrm{O}\right]$ octahedrons, $\left[\mathrm{BO}_{4}\right]$ tetrahedrons and $\left[\mathrm{BO}_{3}\right]$ triangles, which result in a Monoclinic C 2/c sborgite crystal with a low volume packing density of $32.64 \%$ (calculated by CrystalMaker and corrected with first-nearest-neighbor atom overlap). Fig.3b is the unit cell of sborgite with shaded $(-1,3,1)$ plane, which was observed here to be the preferentially developed crystalline plane by XRD. 


\subsection{Microstructural characterization}

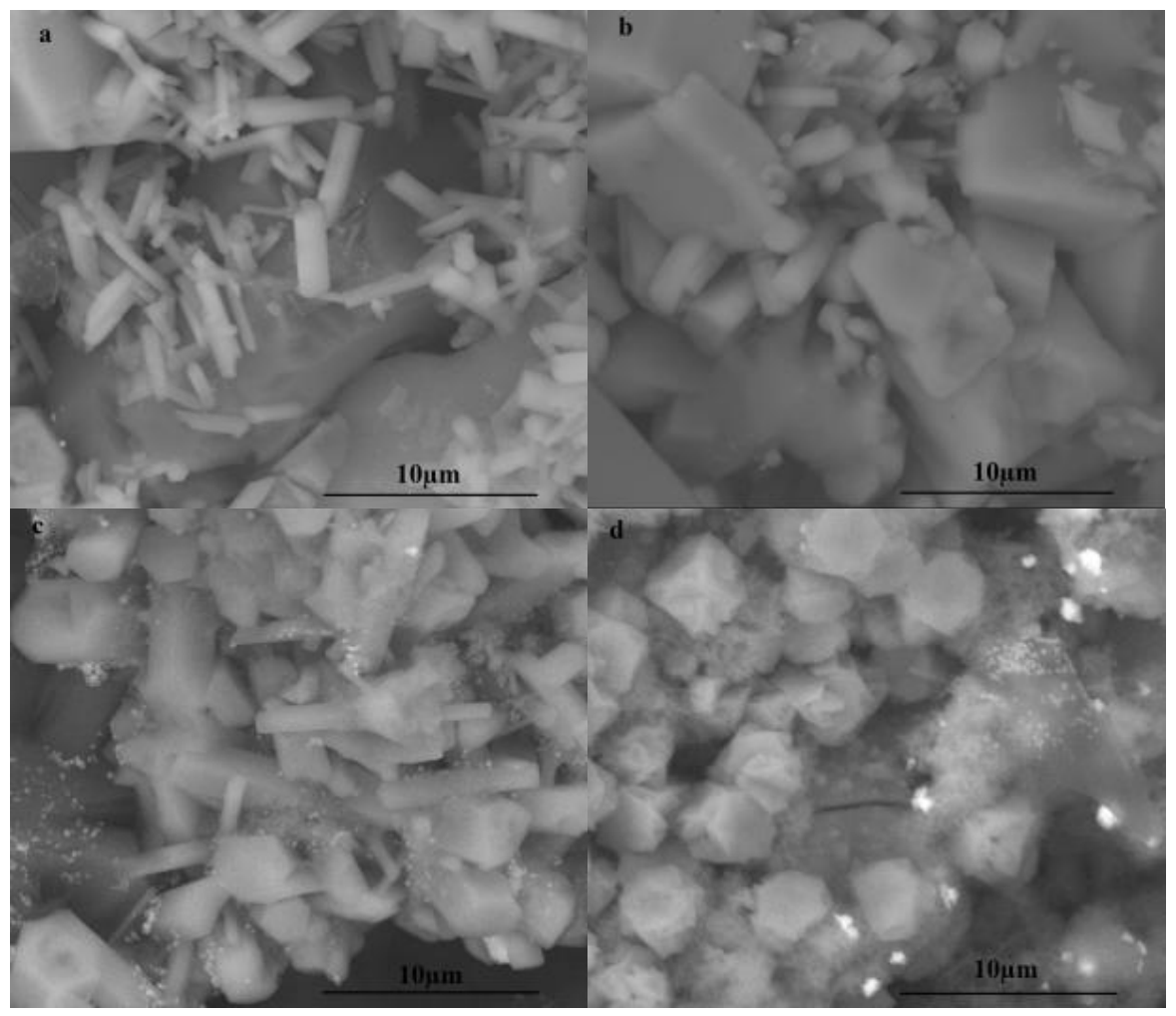

Figure 4 Scanning electron micrographs of a) pre-droplet glass, b) pre-spinodal glass, c) droplet glass and d) spinodal glass after bombed with HF for 10 seconds.

Fig.4a, 4b, 4c, and 4d are SEM images of pre-droplet glass, pre-spinodal glass, droplet glass and spinodal glass after humidity exposure for 1 month. Crystals are clearly shown here and are in agreement with XRD results. It is speculated that such column-like micro-crystal can be attributed to the preferential development of $(-1,3,1)$ plane. Comparisons between the SEM images of homogeneous glasses and liquid phase separated glasses show that the crystalline phase (columnlike micro-crystals) of homogeneous glasses are more developed when compared to phase separated glasses, which is consistent with the XRD results. The bright dots on Fig.4d are likely to be the result of charging of the un-etched glassy phase after HF exposure. 


\section{$\underline{\text { Conclusion }}$}

The findings of this study are summarized as follows:

(1) Single crystalline form sborgite was prepared for the very first time through exposure of four different homogeneous and phase separated sodium-rich borosilicate glasses. We propose sborgite is formed through the preferential reaction of sodium and boron within the homogeneous and phase separated glass structure.

(2) XRD and crystallographic analysis show a preferential development of sborgite, in particular the $(-1,3,1)$ plane, which eventually resulted in a column-like micro-crystal structure, as also evidenced by SEM.

(3) The sborgite crystallization in homogeneous glasses is more prominent compared to their phase separated glass counterparts.

\section{Acknowledgments}

Funding for this work was provided by the Department of Energy Nuclear Engineering University Program (DOE-NEUP) program under contract number DE-AC0705-ID14517. 


\section{$\underline{\text { Reference }}$}

[1] Curzio C, Atti Rend. Accad. Lincei. 1957; 22:519-525.

[2] Pemberton EH, Minerals of California, Van Nostrand Reinholt Press; 1983.

[3] Merlino S, Sartori F, Acta Cryst. 1972; 28:3559-3567.

[4] Kwon IK, Lee SC, Han B, Park K, J. Control. Release. 2012; 164:108-114.

[5] Hu WK, Ye Z, Noréus D, J. Power Sources 2001; 102:35-40

[6] Oi, T, Kato J, Ossaka T, Kakihana H, Geochem J. 1991; 25:377-385

[7] Menchetti S, Sabelli C, Acta Cryst. 1978; B34:45-49

[8] Kumar CJ, Shadiya MA, and et al., J. Am. Ceram. Soc. 2010; 93:3027-3030

[9] Du WF, Kuraoka K, Akai T, and Yazawa T, J. Phys. Chem B 2001; 105:11949-11954

[10] Sun K, Wang LM, and et al., Nucl. Instr. And Meth. in Phys. Res. B 2004; 218:368374

[11] McGahay V, Tomozawa M, J. Non-Cryst. Solids. 1989; 109:27-34 


\section{Figure Captions}

Figure 1 Photos of a) pre-droplet glass, b) pre-spinodal glass, c) droplet glass, d) spinodal glass, e) in-float petri dish setup and f) moisturizing vacuum desiccator.

Figure 2 XRD patterns of all four glasses as a) un-moisturized, b) moisturized for 1 week, c) moisturized for 2 weeks and d) moisturized for 1 month.

Figure 3 a) unit cell crystallographic presentation of sborgite, b) unit cell crystallographic presentation of sborgite with $(-1,3,1)$ plane as red-shaded plane.

Figure 4 Scanning electron micrographs of a) pre-droplet glass, b) pre-spinodal glass, c) droplet glass and d) spinodal glass after bombed with HF for 10 seconds. 


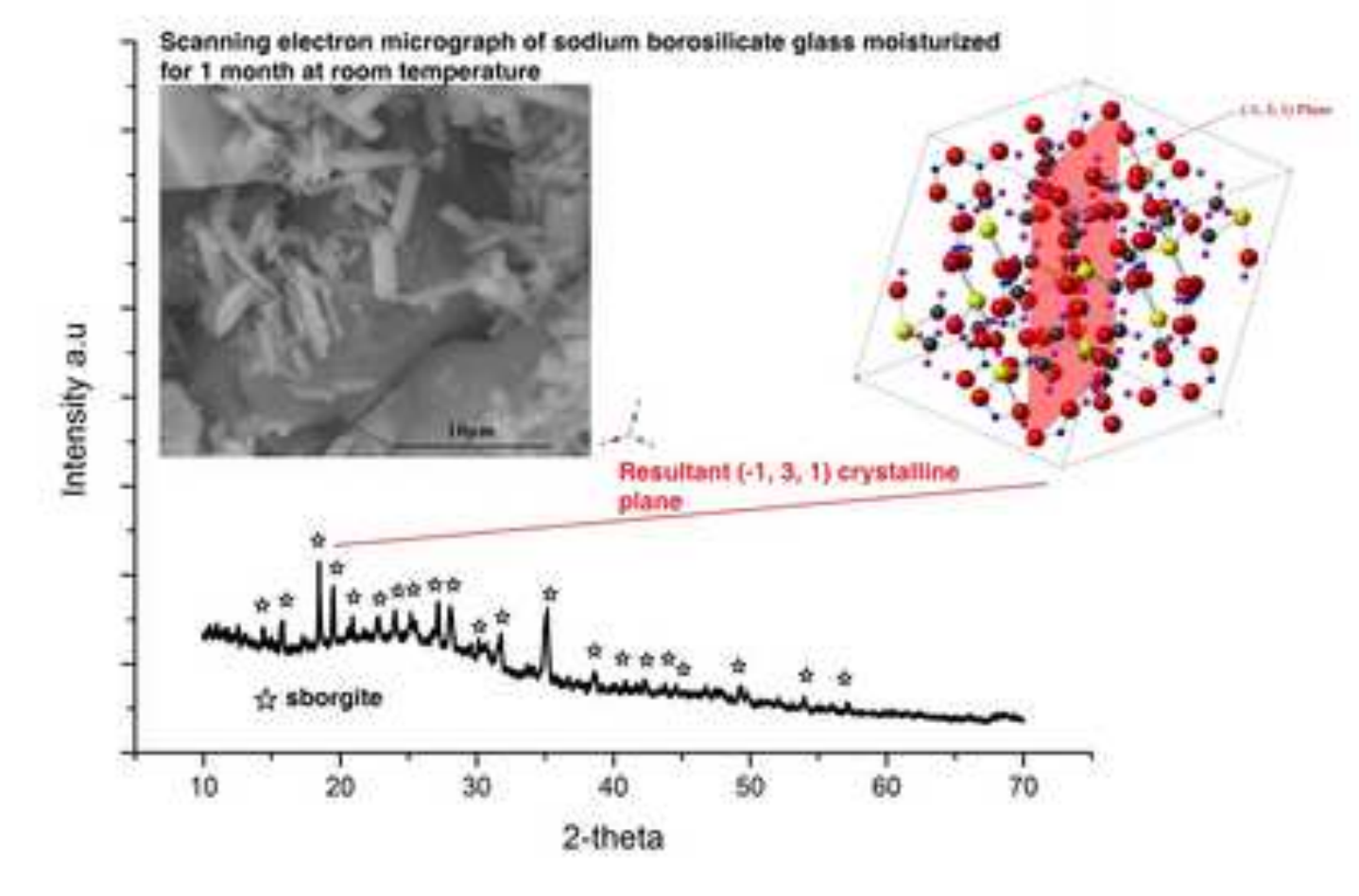

or 1 month at room temperature

Graphical Abstract 